\title{
Effects of an Alkaline Diet on EGFR-TKI Therapy in EGFR Mutation-positive NSCLC
}

\author{
REO HAMAGUCHI $^{1}$, TOSHIHIRO OKAMOTO ${ }^{2}$, MASAAKI SATO ${ }^{1}$, MICHIKO HASEGAWA $^{1}$ and HIROMI WADA ${ }^{1}$ \\ ${ }^{1}$ Karasuma Wada Clinic, Yasaka Karasuma-oike Building 2F, Kyoto, Japan; \\ ${ }^{2}$ Transplant Center, Cleveland Clinic, Cleveland, OH, U.S.A.
}

\begin{abstract}
Background: The acidic tumor microenvironment is associated with progression of cancers. The purpose of this study was to investigate the association between an alkaline diet and the effect of epidermal growth factor receptor (EGFR)-tyrosine kinase inhibitor (TKI) in non-small cell lung cancer (NSCLC) patients. Patients and Methods: Eleven advanced or recurrent NSCLC patients with EGFR mutations treated with EGFR-TKI after being instructed to follow an alkaline diet were retrospectively evaluated. Results: The median progression-free survival (PFS) and overall survival (OS) were 19.5 (range $=3.1-33.8$ ) and 28.5 (range =15.4-46.6) months. The average dosage of EGFRTKI was $56 \pm 22 \%$ of the standard dosage. Urine $p H$ was significantly increased after the alkaline diet $(6.00 \pm 0.38 \mathrm{vs}$. $6.95 \pm 0.55 ; p<0.05)$. Conclusion: An alkaline diet may enhance the effect of EGFR-TKI treatment in NSCLC patients with EGFR mutations.
\end{abstract}

A causative relationship between diet and cancer risk has not been consistently demonstrated. Prospective cohort studies showed no association between vegetable and fruit intake and reduced cancer risk, although case control studies have supported an association $(1,2)$. This inconsistency might be due to confounding factors, poor dietary compliance, and insufficient study duration.

Recent evidence supports the important role of metabolism and inflammation in tumor pathogenesis. A

This article is freely accessible online.

Correspondence to: Reo Hamaguchi, Karasuma Wada Clinic. Yasaka Karasuma-oike Building 2F, Nijodencho 538, Karasumadori Oike Noboru, Nakagyo-ku, Kyoto 604-0845, Japan. Tel: +81 752130080, Fax: +81 752130108, e-mail: reo-h@ nifty.com

Key Words: Non-small cell lung cancer, EGFR mutation, low dose EGFR-TKI, alkaline diet; fruit and vegetables, $\mathrm{pH}$ regulation, urine $\mathrm{pH}$, tumor microenvironment, $\mathrm{Na}^{+} / \mathrm{H}^{+}$exchanger. major transcription factor in inflammation, NF-kB, was involved in the cytotoxic effect of EGFR-TKI; EGFR mutation-positive lung cancer cells were sensitive to NF-kB inhibition (3). Insulin and insulin-like growth factors might stimulate tumor cell growth, based on the association between diabetes and increased risk of cancers. One metaanalysis showed that the anti-diabetic drug metformin was associated with lower cancer incidence in type 2 diabetes (4).

To date it was understood that cancer cells produce energy via high rates of glycolysis to support their rapid cell cycle (Warburg effect). Many researchers have demonstrated that the $\mathrm{pH}$ of the tumor microenvironment is acidic due to lactic acid accumulation through the Warburg effect $(5,6)$. Moreover, the carbonic anhydrase isozyme CA9 is ectopically overexpressed in solid tumors, especially in the setting of hypoxia. This enzyme catalyzes the hydration of carbon dioxide to bicarbonate and $\mathrm{H}^{+}$. Amith et al. reported that the activity of $\mathrm{Na}^{+} / \mathrm{H}^{+}$exchanger is enhanced on breast cancer cell membranes, which contributes to cytoplasmic alkalization and local extracellular acidosis that regulates tumor proliferation and progression (7). $\mathrm{Na}^{+} / \mathrm{H}^{+}$exchanger is also reported to activate cofilin-1, which is involved in the actin cytoskeleton signaling and plays a key role in cancer cell migration (8). Therefore, altering $\mathrm{pH}$ homeostasis in and around tumor cells might be a critical component of cancer treatment. The purpose of this study was to investigate the association between an alkaline diet and the effect of EGFRTKI in lung cancer patients with EGFR mutations.

\section{Patients and Methods}

Patients. Of the 146 NSCLC patients who visited the Karasuma Wada Clinic between April 2013 and March 2015, there were a total of 45 patients with EGFR mutations who had advanced or recurrent NSCLC. We retrospectively analyzed 11 of these NSCLC patients who were given instructions to change their daily diet to an alkaline diet and then were treated with EGFR-TKI for the first time, regardless of whether they had previously received other treatments. We excluded 25 patients who had previously been treated with EGFR-TKI, 4 patients who did not receive EGFR-TKI treatment, 4 patients who visited our clinic less 
than 3 times and whose courses of treatment were unclear, and 1 patient who could not continue EGFR-TKI treatment because of liver dysfunction. All procedures were performed in accordance with the ethical principles expressed in the 1995 Declaration of Helsinki. The institutional review board of the Japan-Multinational Trial Organization (JMTO) approved this retrospective study.

Treatment. The patients in this study were treated with gefitinib, erlotinib, or afatinib. In all cases, the dose of EGFR-TKI was reduced owing to its adverse reactions. This is because several studies have reported that low-dose EGFR-TKI for NSCLC with EGFR mutations produces effective treatment responses similar to treatment with standard dose (9-12). Therefore, the patients were treated with the following doses; gefitinib: 125-250 mg/day, erlotinib: $25-100 \mathrm{mg} /$ day, afatinib: $20-40 \mathrm{mg} /$ day. An alkaline diet was defined as that with more vegetables and fruits and less meat and dairy products. All patients in our clinic were given instructions to follow an alkaline diet as part of routine clinical care. At every visit, a doctor or nurse provided patients with instructions on an alkaline diet and assessed whether patients had been following an alkaline diet regularly.

Assessment procedures. Patients were evaluated for their antitumor response to EGFR-TKI therapy using computed tomography (CT) scans of the head, chest, and abdomen, or positron emission tomography/computed tomography at intervals decided by the physician. Treatment responses were defined in accordance with the Response Evaluation Criteria in Solid Tumors group (RECIST, version 1.1). Urine $\mathrm{pH}$ was analyzed at the patients' regular visits, between 1 to 4 times in 2 months.

Statistical analyses. We analyzed the data on April 30, 2017. PFS and OS were calculated using Kaplan-Meier estimates. OS is shown from the start of an alkaline diet. The dosage of EGFR-TKI is expressed as a percentage of the standard dosage. The paired t-test was used to compare the difference between urine $\mathrm{pH}$ before having an alkaline diet and after having an alkaline diet. Average $\mathrm{pH}$ value was calculated in each patient before and after having an alkaline diet and utilized in the analysis. Mean data set values are presented with \pm standard deviation. All $p$-values were two sided and $p$-values of less than 0.05 were considered statistically significant. All statistical analyses were performed with EZR (version 1.32) (Saitama Medical Center, Jichi Medical University, Saitama, Japan) (13), that is a graphical user interface for modified version of $\mathrm{R}$ (The R Foundation for Statistical Computing, Vienna, Austria).

\section{Results}

The median age was 64.4 (range=49-73) years, and there were 6 men and 5 women. Histological examination confirmed that 7 patients had adenocarcinoma and 4 patients had non-small cell carcinoma. Seven patients were recurrent and 4 patients were clinical stage IV. Seven patients had previously undergone chemotherapy before receiving EGFRTKI treatment. All patients received reduced dosage of EGFR-TKI treatment, and the average dosage of EGFR-TKI was $56 \pm 22 \%$ of the standard dosage (Figure 1).

The median PFS was 19.5 (range=3.1-33.8) months, as shown in Figure 2A, and the median OS was 28.5 (15.4-

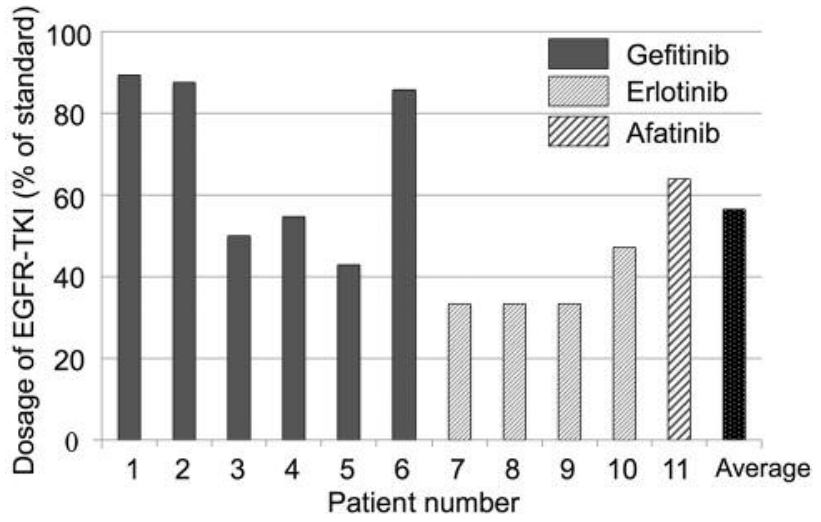

Figure 1. Dosage of EGFR-TKI. The average dosage of EGFR-TKI administered to each patient is shown as a percentage of the standard dosage.

46.6) months, as shown in Figure 2B. Two of the 11 patients have died as of April 2017.

Figure 3 shows the average urine $\mathrm{pH}$ of the patients before having an alkaline diet and after having an alkaline diet, until confirmation of progressive disease. A significant difference was observed between urine $\mathrm{pH}$ before and after the alkaline $\operatorname{diet}(6.00 \pm 0.38 v s .6 .95 \pm 0.55 ; p<0.05)$.

\section{Discussion}

The most important finding in this report was that the case series of 11 advanced lung cancer patients demonstrated long progression-free survival and overall survival following the combination therapy of low-dose EGFR-TKI with an alkaline diet. The progression-free survival (median=19.5 months) and overall survival (median=28.5 months) of this group was longer than that reported in publications of the similar population treated with EGFR-TKI alone (median progressionfree survival=9.2-13.3 months, median overall survival=18.622.8 months) (14-18). EGFR-TKI therapy has prolonged progression-free survival of advanced EGFR-mutation positive NSCLC compared to platinum-based chemotherapy, whereas the therapeutic potential of EGFR-TKIs might be limited due to resistance and toxicity $(19,20)$. Although this is a preliminary observation in the absence of a comparator group, the consistent outcomes of these 11 cases might suggest the importance of a new regimen that includes an alkaline diet.

In this study, urine $\mathrm{pH}$ significantly increased from baseline following initiation of an alkaline diet regimen. Urine $\mathrm{pH}$ is an important factor in the development and treatment of kidney stones. For example, the treatment of calcium oxalate stones involves urinary alkalization with sodium or potassium citrate. Besides pharmacologic alkalization, dietary modification also contributes to treatment success. Fruit 


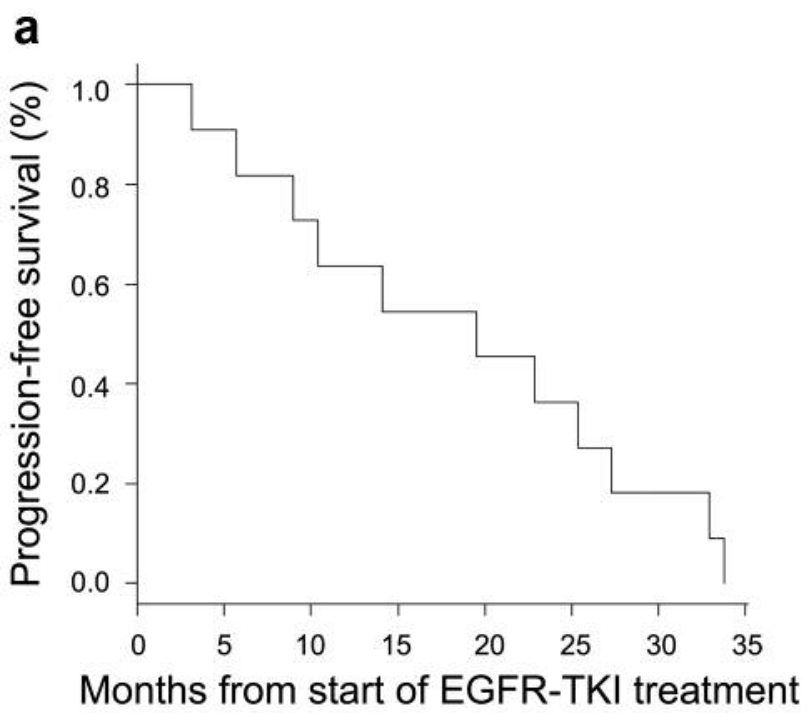

b

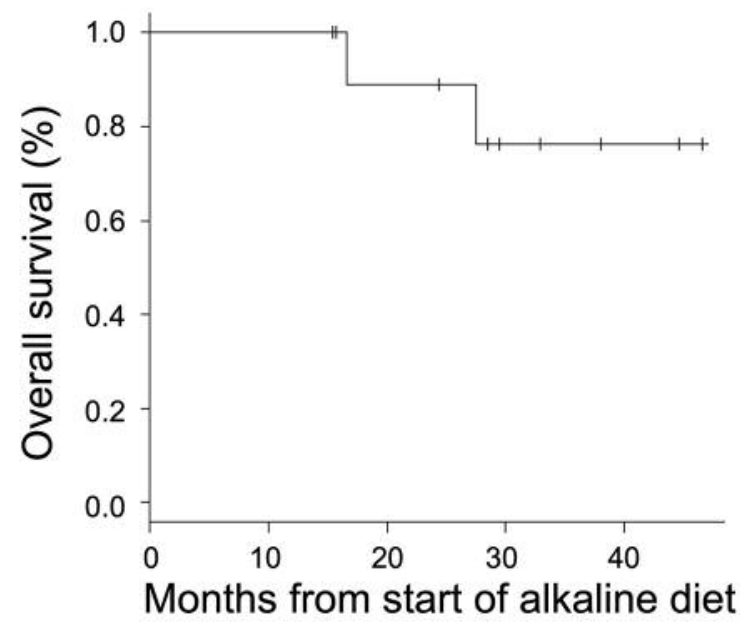

Figure 2. (A) Progression-free survival; Kaplan-Meier curve of the progression-free survival. (B) Overall survival; Kaplan-Meier curve of the overall survival from the start of an alkaline diet.

contains alkalotic precursors such as citrate, succinate and malate, which generate bicarbonate. In a study investigating food's influence on urine $\mathrm{pH}$, potential renal acid load was calculated to quantify the acid and base precursors present in food and to predict renal net acid excretion (positive means acidic). Meat had a potential renal acid load of $+9.5 \mathrm{mEq}$, while fruit was $-3.1 \mathrm{mEq}$ and vegetables were $-2.8 \mathrm{mEq}$ (21). In the European Prospective Investigation into Cancer and Nutrition-Norfolk population (EPIC) study $(n=22,038)$, alkaline diet with high fruit and vegetable and low meat intake was significantly associated with more alkaline urine (22). The change in urine $\mathrm{pH}$ following an alkaline diet observed in this study was consistent with the EPIC study.

It is difficult to dramatically alter the $\mathrm{pH}$ of blood through an alkaline diet, since acid-base balance is maintained by blood and tissue buffers, respiratory $\mathrm{CO}_{2}$ depletion, and renal regulation of $\mathrm{H}^{+}$excretion and $\mathrm{HCO}_{3}{ }^{+}$regeneration. However, both a mathematical model and rat experimental model demonstrated that oral sodium bicarbonate raises extracellular $\mathrm{pH}$ of tumor cells $(23,24)$. In addition, Robey et al. reported that sodium bicarbonate was significantly associated with reduced number of metastases in rat breast cancer model (24). This group advocated buffer therapy with sodium bicarbonate to alkalinize urine, neutralize near-tumor acidity, and inhibit tumor metastasis. Our approach with an alkaline diet is similar to buffer therapy, linked by the common concept that intake of an alkaline agent increased urine $\mathrm{pH}$ and had an anti-cancer effect. Therefore, these animal data support the association between urinary alkalization and prolonged survival in this study.

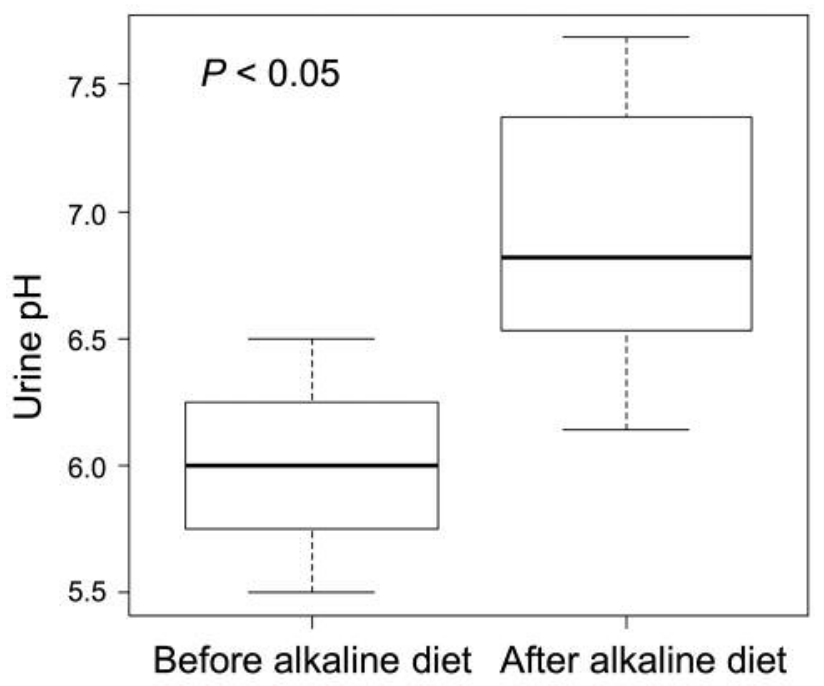

Figure 3. Effect of an alkaline diet on urine $\mathrm{pH}$. The average urine $\mathrm{pH}$ was compared before and after having an alkaline diet $(n=11)$.

We acknowledge that there exist several limitations. First, this study was a retrospective analysis and the sample size was small. Second, lower dosage of EGFR-TKI than the standard was given mainly owing to adverse reactions in this study. Several studies have reported that low-dose EGFRTKI for EGFR-mutant lung cancer resulted in effective treatment responses (9-12). Third, although we showed changes in urine $\mathrm{pH}$ in this study, we did not analyze the 
extracellular $\mathrm{pH}$ surrounding cancer cells. However, it is difficult to measure the extracellular $\mathrm{pH}$ of cancer cells in an actual clinical setting, and hence further investigation of the association between extracellular $\mathrm{pH}$ and urine $\mathrm{pH}$ is necessary.

\section{Conclusion}

This study demonstrated prolonged progression-free survival and overall survival with the regimen of low-dose EGFRTKI and an alkaline diet. The significant increase of urine $\mathrm{pH}$ suggests that the local acidic $\mathrm{pH}$ of tumor might be at least partially neutralized. To the best of our knowledge, this may be the first clinical evidence that an alkaline diet might be associated with better outcomes of advanced lung cancer patients.

\section{Acknowledgements}

The Authors acknowledge Matthew Blum, MD, for his editorial support.

\section{References}

1 Key TJ: Fruit and vegetables and cancer risk. Br J Cancer 104: 6-11, 2011.

2 Benetou V, Orfanos P, Lagiou P, Trichopoulos D, Boffetta P and Trichopoulou A: Vegetables and fruits in relation to cancer risk: evidence from the Greek EPIC cohort study. Cancer Epidemiol Biomarkers Prev 17: 387-392, 2008.

3 Bivona TG, Hieronymus H, Parker J, Chang K, Taron M, Rosell R, Moonsamy P, Dahlman K, Miller VA, Costa C, Hannon G and Sawyers CL: FAS and NF-kB signalling modulate dependence of lung cancers on mutant EGFR. Nature 471: 523-526, 2011.

4 Decensi A, Puntoni M, Goodwin P, Cazzaniga M, Gennari A, Bonanni B and Gandini S: Metformin and cancer risk in diabetic patients: a systematic review and meta-analysis. Cancer Prev Res (Phila) 3: 1451-1461, 2010.

5 Neri D and Supuran CT: Interfering with $\mathrm{pH}$ regulation in tumours as a therapeutic strategy. Nat Rev Drug Discov 10: 767777, 2011.

6 Zhou W, Liotta LA and Petricoin EF: The Warburg effect and mass spectrometry-based proteomic analysis. Cancer Genomics Proteomics 14: 211-218, 2017.

7 Amith SR and Fliegel L: Regulation of the $\mathrm{Na}^{+} / \mathrm{H}^{+}$Exchanger (NHE1) in Breast Cancer Metastasis. Cancer Res 73: 1259-1264, 2013.

8 Pappa KI, Lygirou V, Kontostathi G, Zoidakis J, Makridakis M, Vougas K, Daskalakis G, Polyzos A and Anagnou NP: Proteomic analysis of normal and cancer cervical cell lines reveals deregulation of cytoskeleton-associated proteins. Cancer Genomics Proteomics 14: 253-266, 2017.

9 Hirano R, Uchino J, Ueno M, Fujita M and Watanabe K: Lowdose epidermal growth factor receptor (EGFR)-tyrosine kinase inhibition of EGFR mutation-positive lung cancer: therapeutic benefits and associations between dosage, efficacy and body surface area. Asian Pac J Cancer Prev 17: 785-789, 2016.
10 Yeo WL, Riely GJ, Yeap BY, Lau MW, Warner JL, Bodio K, Huberman MS, Kris MG, Tenen DG, Pao W, Kobayashi S and Costa DB: Erlotinib at a dose of $25 \mathrm{mg}$ daily for non-small cell lung cancers with EGFR mutations. J Thorac Oncol 5: 10481053, 2010.

11 Szejniuk WM, McCulloch T and Røe OD: Effective ultra-low doses of erlotinib in patients with EGFR sensitising mutation. BMJ Case Rep 23: 2014, 2014.

12 Satoh H, Inoue A, Kobayashi K, Maemondo M, Oizumi S, Isobe H, Gemma A, Saijo Y, Yoshizawa H, Hagiwara K and Nukiwa T: Low-dose gefitinib treatment for patients with advanced nonsmall cell lung cancer harboring sensitive epidermal growth factor receptor mutations. J Thorac Oncol 6: 1413-1417, 2011.

13 Kanda Y: Investigation of the freely available easy-to-use software 'EZR' for medical statistics. Bone Marrow Transplant 48: 452-458, 2013.

14 Mok TS, Wu YL, Thongprasert S, Yang CH, Chu DT, Saijo N, Sunpaweravong P, Han B, Margono B, Ichinose Y, Nishiwaki Y, Ohe Y, Yang JJ, Chewaskulyong B, Jiang H, Duffield EL, Watkins CL, Armour AA and Fukuoka M: Gefitinib or carboplatin-paclitaxel in pulmonary adenocarcinoma. N Engl J Med 361: 947-57, 2009.

15 Mitsudomi T, Morita S, Yatabe Y, Negoro S, Okamoto I, Tsurutani J, Seto T, Satouchi M, Tada H, Hirashima T, Asami K, Katakami N, Takada M, Yoshioka H, Shibata K, Kudoh S, Shimizu E, Saito H, Toyooka S, Nakagawa K, Fukuoka M; West Japan Oncology Group: Gefitinib versus cisplatin plus docetaxel in patients with non-small-cell lung cancer harbouring mutations of the epidermal growth factor receptor (WJTOG3405): an open label, randomised phase 3 trial. Lancet Oncol 11: 121-128, 2010.

16 Miyauchi E, Inoue A, Kobayashi K, Maemondo M, Sugawara S, Oizumi S, Isobe H, Gemma A, Saijo Y, Yoshizawa H, Hagiwara K, Nukiwa T; North-East Japan Study Group: Efficacy of chemotherapy after first-line gefitinib therapy in EGFR mutation-positive advanced non-small cell lung cancer-data from a randomized Phase III study comparing gefitinib with carboplatin plus paclitaxel (NEJ002). Jpn J Clin Oncol 45: 670676, 2015.

17 Zhou C, Wu YL, Chen G, Feng J, Liu XQ, Wang C, Zhang S, Wang J, Zhou S, Ren S, Lu S, Zhang L, Hu C, Hu C, Luo Y, Chen L, Ye M, Huang J, Zhi X, Zhang Y, Xiu Q, Ma J, Zhang L and You C: Erlotinib versus chemotherapy as first-line treatment for patients with advanced EGFR mutation-positive non-smallcell lung cancer (OPTIMAL, CTONG-0802): a multicentre, open-label, randomised, phase 3 study. Lancet Oncol 12: 735$742,2011$.

18 Park K, Tan EH, O'Byrne K, Zhang L, Boyer M, Mok T, Hirsh V, Yang JC, Lee KH, Lu S, Shi Y, Kim SW, Laskin J, Kim DW, Arvis CD, Kölbeck K, Laurie SA, Tsai CM, Shahidi M, Kim M, Massey D, Zazulina V and Paz-Ares L: Afatinib versus gefitinib as first-line treatment of patients with EGFR mutation-positive non-small-cell lung cancer (LUX-Lung 7): a phase 2B, open-label, randomised controlled trial. Lancet Oncol 17: 577-589, 2016.

19 Lee CK, Brown C, Gralla RJ, Hirsh V, Thongprasert S, Tsai CM, Tan EH, Ho JC, Chu da T, Zaatar A, Osorio Sanchez JA, Vu VV, $\mathrm{Au}$ JS, Inoue A, Lee SM, Gebski V and Yang JC: Impact of EGFR inhibitor in non-small cell lung cancer on progressionfree and overall survival: a meta-analysis. J Natl Cancer Inst 105: 595-605, 2013. 
20 Isobe K, Hata Y, Tochigi N, Kaburaki K, Kobayashi H, Makino T, Otsuka H, Ishida F, Hirota N, Sano G, Sugino K, Sakamoto S, Takai Y, Shibuya K, Iyoda A and Homma S: Usefulness of nanofluidic digital PCR arrays to quantify T790M mutation in EGFR-mutant lung adenocarcinoma. Cancer Genomics Proteomics 12: 31-7, 2015.

21 Remer T and Manz F: Potential renal acid load of foods and its influence on urine pH. J Am Diet Assoc 95: 791-797, 1995.

22 Welch AA, Mulligan A, Bingham SA and Khaw KT: Urine pH is an indicator of dietary acid-base load, fruit and vegetables and meat intakes: results from the European Prospective Investigation into Cancer and Nutrition (EPIC)-Norfolk population study. Br J Nutr 99: 1335-1343, 2008
23 Martin NK, Gaffney EA, Gatenby RA, Gillies RJ, Robey IF and Maini PK: A mathematical model of tumour and blood $\mathrm{pHe}$ regulation: The $\mathrm{HCO}_{3}-/ \mathrm{CO}_{2}$ buffering system. Math Biosci 230: 1-11, 2011.

24 Robey IF, Baggett BK, Kirkpatrick ND, Roe DJ, Dosescu J, Sloane BF, Hashim AI, Morse DL, Raghunand N, Gatenby RA and Gillies RJ: Bicarbonate increases tumor $\mathrm{pH}$ and inhibits spontaneous metastases. Cancer Res 69: 2260-2268, 2009.

Received July 2, 2017

Revised July 17, 2017

Accepted July 24, 2017 